\title{
AN EXPLANATION OF THE GROWTH OF SOCIAL SECURITY DISABILITY TRANSFERS
}

BY

FRANS A.J. VAN DEN BOSCH AND CAREL PETERSEN*

\section{INTRODUCTION}

In most European countries the continuing growth of the costs of social security constitutes a severe economic problem. Expressed as a percentage of the Gross Domestic Product social security transfer incomes have on average increased from $18 \%$ in 1970 to $25 \%$ in 1979 in the E.E.C. countries. ${ }^{1}$ Disability programmes are one of the fastest-growing subsectors within the social security sector, although the size per country differs remarkably. ${ }^{2}$

In the literature a few attempts have been made to explain the growth of disability programmes at a macro level (e.g. Van Praag and Halberstadt (1980), Lando (1979) and Hambor (1975)). These studies show that the growth of the volume of disability beneficiaries, and thus the costs of disability programmes, can to a considerable degree be attributed to the worsened economic situation in the 1970's. ${ }^{3}$ However, at a meso level the growth of the volume of disability beneficiaries per branch of industry differs remarkably, at least in the Netherlands. Consequently, analysis of the determinants

* A draft of this paper was presented at the symposium 'Some Economic Aspects of Disability,' Erasmus University Rotterdam, The Netherlands, October 1981. Both authors are affiliated with the Department of Economics of the Erasmus University Rotterdam, P.O. Box 1738, 3000 DR Rotterdam. They wish to thank especially Professor Jan Tinbergen, Professor Bernard van Praag, Mr. Philip de Jong and Mr. Peter Kooiman for their interest in the subject and their valuable comments on a earlier draft of this paper. The authors are grateful to Saam de Mooy for his computational assistance.

1 This is the unweighted average. Source: EEC, Eurostat, Demographic and Social Statistics, 2 - 1981.

2 Expressed as a percentage of Gross Domestic Product disability transfers have on the average increased by about 50\% in the period 1970-1979 in the E.E.C. countries (see also Copeland (1981) and Haveman and Halberstadt (forthcoming)).

3 For a recent survey with respect to the influence of disability insurance on, among others, factor supply, see Danziger et al. (1981). 
of growth in the volume of disability beneficiaries at a meso level, which is the main aim of the present paper, constitutes a fruitful basis for a more thorough analysis of the growth of social security disability transfers.

For this purpose we have made use of a conceptual framework. From this framework we have deduced an empirically testable disability model. Section 2 presents a brief overview of the structure of Dutch disability programmes. The conceptual framework is developed in section 3 . The model to be tested and the empirical evidence is presented in section 4. Finally, some concluding remarks are presented in section 5 .

\section{A SHORT OUTLINE OF DUTCH DISABILITY PROGRAMMES}

During the first year of disability to work due to illness or accident (including occupational risks) an employee in the private sector of the Dutch economy is entitled to a sickness benefit. If he is still disabled after one year, he is awarded a benefit on the basis of the Disability Security Act. ${ }^{4}$ In case of prolonged disability an employee in the public sector is awarded a benefit on the basis of the General Public Pensions Act.

The most relevant features of both disability programmes are (a) dependent on the degree of disability, the benefit is a percentage of the last earned wage up to a maximum of $80 \%$; (b) the minimum required degree of disability to be eligible for a benefit is only $15 \%$; and (c) save recovery or death, there is no maximum duration of the benefit up to the age of $65^{5}$ (for more details see e.g. Commission of European Communities (1978)). The only essential difference between the two programmes is the period between the first day of disability and the moment a disability benefit is awarded. In the private sector this period is fixed at one year, whereas in the public sector, depending on the prospects of the development of the disability, this period is on average about 2 years.

4 Abbreviated: DSA. This act was introduced on July 1, 1967. As from that date beneficiaries of displaced disability programmes receive a DSA award. We have disregarded the General Disability Security Act, introduced in 1976, which is not essential for our analysis.

5 The same legal structure is applicable to all branches of industry. This means that, among others, the ratio of potential disability benefit to wage does not differ significantly by branch of industry. 
The growth of the real costs of disability transfers is caused both by an increase of the average real value of the disability benefits and the number of disability beneficiaries. However, it appears that in the period being investigated (1968-1979) the growth of the volume of beneficiaries amounts to $200 \%$ and thereby dominates the growth of the average real value of the disability benefits, which amounts to $45 \%$. In this paper we will restrict ourselves to an explanation of the growth of the number of disability beneficiaries. Since the termination pattern of disability beneficiaries remains fairly stable, the most important determinant of growth is the so-called disability incidence rate, i.e. the number of new disability awards in a certain year per 100 insured persons. The disability incidence rate in the private sector has increased from $1.2 \%$ in 1968 to $2.1 \%$ in 1979 , resulting in an increase in the total volume of disability beneficiaries from 160,000 in 1968 to 480,000 in 1979 .

Table 1 shows that the development of the disability incidence rate per branch of industry varies remarkably. It appears that the textile industry shows the greatest absolute increase while banking, insurance and business services show the lowest absolute increase of the disability incidence rate.

We will use a conceptual framework to investigate the determinants of this diverging development. This framework forms an extension in relation to the literature by also introducing the perceived state of health as an explanatory variable. The hypothesis is that the disability incidence rate in both the private and the public sector can be explained by the following variables (see also Van den Bosch and Petersen $(1979,1983))^{6}$ :

$$
D R=f(H, P H, L, O, E)
$$

where $D R$ stands for the disability incidence rate, $H$ for health, $P H$ for perceived state of health, $L$ for legal structure, $O$ for occupation and $E$ for economic factors.

A worsening state of health $(H)$ will increase the chance of disability. In addition to the more or less objective health indicator $H$, current values and norms with respect to whether it is socially and personally acceptable to feel oneself entitled to a benefit $(P H)$ will play a role (see Lando (1974) and Schechter (1981)). The legal structure $(L)$, notably criteria governing eligibility

6 See for an analysis of disability by age Van den Bosch and Petersen (1982) and, in this connection, for a vintage approach applied to labour Van den Bosch (1982). 
TABLE 1 - NUMBER OF NEW DISABILITY AWARDS EXPRESSED AS A PERCENTAGE OF THE NUMBER OF INSURED EMPLOYEES (DISABILITY INCIDENCE RATE); THE NETHERLANDS, 1968-1979

\begin{tabular}{llll}
\hline Branch of industry & & \\
& \multicolumn{2}{l}{$\begin{array}{l}\text { Disability } \\
\text { rate }(\%)\end{array}$} & \\
& 1968 & 1979 & $1968-1979$ \\
\hline 1. Construction & 2.0 & 3.0 & 1.0 \\
2. Timber and furniture & 1.5 & 2.6 & 1.1 \\
3. Textile & 1.6 & 3.9 & 2.3 \\
4. Clothing & 0.9 & 2.3 & 1.4 \\
5. Leather and footwear & 1.1 & 2.6 & 1.5 \\
6. Printing & 1.2 & 2.3 & 1.1 \\
7. Stone and cement & 1.7 & 3.6 & 1.9 \\
8. Basic metal and electrical & 1.2 & 2.6 & 1.4 \\
9. Fabricated metal products, & & & \\
$\quad$ machinery and equipment & 0.9 & 1.9 & 1.0 \\
10. Chemical & 1.5 & 2.5 & 1.0 \\
11. Tobacco & 1.2 & 2.1 & 0.9 \\
12. Meat, etc. & 0.8 & 2.6 & 1.8 \\
13. Food & 1.1 & 2.6 & 1.5 \\
14. Retail trade and crafts & 0.7 & 1.6 & 0.9 \\
15. Hotels, restaurants, etc. & 1.7 & 2.4 & 0.7 \\
16. Banking, insurance and & & & \\
business services & 0.8 & 1.4 & 0.6 \\
Total insured employees private & & & \\
sector & 1.2 & 2.1 & 0.9 \\
Total insured employees public & & & \\
sector & 0.5 & 1.1 & 0.6 \\
\hline
\end{tabular}

a The abovementioned branches of industry encompass $70 \%$ of the total number of persons insured under the DSA. The remaining branches have not been taken into account in view of the very specific groups of insured persons involved, e.g. agriculture, which would complicate the analysis unnecessarily.

Source: Annual Reports of Industry Association, The Disabled Persons Fund, The Joint Medical Service and the General Public Pension Statistics (1968-1979).

and benefit determination, may also contribute to the explanation of the disability incidence rate. As some occupations are of a more physically demanding nature (e.g. the construction sector) or of a more mentally demanding nature than others, it is obvious that account should be taken of the type of occupation $(O)$. Because, at least in principle, employers maximize profits, it is rational to assume that economic factors $(E)$ will also influence the dis- 
ability incidence rate. For, given the rather rigid wage structure, employers will be inclined to dismiss those employees first who are least productive, e.g. due to handicaps, if the economic development is worsening (see Van Praag and Emanuel (1983), Lando, (1974)).

Because a disability benefit is generally more attractive, both financially and from the point of view of social acceptance, than unemployment benefits, potentially unemployed persons will, if possible, prefer a disability to an unemployment benefit in the Netherlands. The importance of the labourmarket situation in this country has recently been clearly stressed by the OECD: 'Normally benefits are linked to the degree of disability as established by the social security system and to the previous income. In the slack labour market conditions of the last few years, however, it was felt that even minor disablement was a major disadvantage to a job-seeker, so there has been a general uprating of degrees of disability leading to more generous benefits.' (OECD (1981), p. 35).

\subsection{Explanatory Variables}

In this section we will specify the hypothesized relationship and consequently test the plausibility of the conceptual framework at a meso level, i.e. per branch of industry for the period 1968-1979. Since we are interested in the growth of the disability incidence rate per branch of industry, we must first analyse the change of the explanatory variables.

We have, as is usual, employed the development of mortality as a proxy for change in the state of health (see e.g. Doherty (1979)). Given the slightly declining mortality rates of the Dutch population (standardized for age and sex) in combination with the decreasing average age of the insured, it is plausible to assume that state of health at least remains constant or may even have improved slightly in the period under consideration. ${ }^{7}$ The legal structure has also remained essentially the same in this period. Furthermore, there is no indication that the type of work per branch of industry was on the average more demanding in 1979 than it was in 1968. This leaves two variables in explanation of growth of the disability incidence rate, namely the perceived

7 For the sake of completeness it must be remarked that the development of the age and sex structure per branch of industry has also been analysed. However, it appears that during the period under consideration both the average age and the percentage of women per branch of industry has remained fairly constant. 
state of health and economic factors. As a proxy for economic development per branch of industry we have used two alternative variables, namely the share of profits (or more precisely, nonlabour income) in value added by industry and the number of employed.

The influence of the perceived state of health is approximated by the development of the corrected disability incidence rate in the public sector of the economy, for in the public sector profit maximizing behaviour of the employers is of only minor importance. ${ }^{8}$ It follows that according to the conceptual framework the growth of the disability incidence rate in the public sector is only determined by the altered perceived state of health. For in the public sector as in the private sector the explanatory variables with respect to state of health, legal structure, and occupational structure have not changed.

\subsection{The Regression Model}

From the above it follows that the disability model to be tested is

$$
\begin{aligned}
& \triangle D R_{i, t}=\alpha_{i}+\beta \Delta P H_{t}+\gamma_{i} \Delta E_{i, t-1}+D ; t=1969 \ldots 1979 \text { and } i= \\
& 1, \ldots 16 .
\end{aligned}
$$

$\triangle D R_{i, t}$ being the change of disability incidence rate per branch of industry $i$ in year $t$ with regard to the disability incidence rate in that branch of industry in the base year 1968. $P H_{t}$ stands for the perceived state of health. According to the last section the development of this explanatory variable is approximated by the change in the disability incidence rate in the public sector in year $t$ in relation to the disability incidence rate in the public sector in 1968. It has to be stressed that the branch of industry subscript $i$ is missing here, for it is plausible that the influence of a change of $P H$ on the disability incidence rate does not differ per branch of industry.

The economic variable $E_{i, t-1}$ is operationalized by the change of the index of the share of profits in value added per branch of industry $i$ in year $t$-1 in relation to 1967 . Alternatively the economic variable is operationalized by the change of the index of the number of employed persons per branch

8 In order to make the disability incidence rates of the private and public sectors comparable we have made two corrections. Firstly, with respect to the difference in waiting period (see paragraph 2). Secondly, the average age in the public sector is approximately 5 years higher than in the private sector. By standardizing the disability incidence rate of the public sector with the age distribution in the private sector we have made comparison possible on this point, too. (For further details see: Van den Bosch and Petersen (1979)). 
of industry $i$ in year $t-1$ in relation to $1967 . .^{9}$ In view of the one-year waiting period before a disability benefit is awarded, a time lag of one year has been applied. In addition, a dummy $(D)$ is incorporated because of the oil crisis in 1973 because, as a consequence of the oil crisis, economic growth has structurally slowed down. This means that the expectations of both employers (concerning e.g. costs and sales) and of employees (with respect to employment prospects or opportunities) have become considerably less favourable since 1973.

On the basis of the conceptual framework the hypothesis is, that the sign of $\beta$ will be positive, for a 'deterioration' of the perceived state of health will increase the disability incidence rate. On the contrary $\gamma$ must be negative, for better economic conditions will decrease the disability incidence rate. If our assumption is correct, the coefficient with respect to the dummy must be positive. Finally it must be remarked that in view of the short period under observation the regression analysis employed is a combination of crosssection and time-series analysis (for a similar approach see e.g. Barro et al. (1979)). As it is quite likely that the influence of economic factors on the disability incidence rate varies per branch of industry, we have applied individual intercepts $\left(\alpha_{i}\right)$ and coefficients $\left(\gamma_{i}\right)$ per branch of industry. ${ }^{10}$ Besides, branches of industry vary in size. The results presented below are thus in both weighted and unweighted form. The weight per branch of industry in each year is the square foot of the average number of employed persons in that year. ${ }^{11}$

\subsection{Empirical Results}

The basic empirical results are presented in tables $2 \mathrm{a}$ and $2 \mathrm{~b}$. The first four columns of both tables relate to the unweighted regressions, the last four columns deal with weighted regressions. As indicator of economic development table 2a contains the employment variable $E M I_{i, t-1}$, whereas in table $2 \mathrm{~b}$ the profit variable $\left(S P I_{i, t-1}\right)$ is used as economic indicator.

Consider first the results presented in table $2 \mathrm{a}$. Both the unweighted and the weighted form show a good fit. It has to be remarked that the regression result of the weighted form is slightly better. Further, in both forms all the

9 We have used an index number for the explanatory variables per branch of industry since the absolute level of e.g. the profit share by branch of industry is not comparable. For data and description see: Van den Bosch and Petersen (1981a).

10 The 0 -hypothesis that the intercepts are equal has to be rejected on the basis of a $F$-test on the $1 \%$ significance level.

11 Alternatively an average weight per branch of industry has been used. The results, however, only slightly differ. 


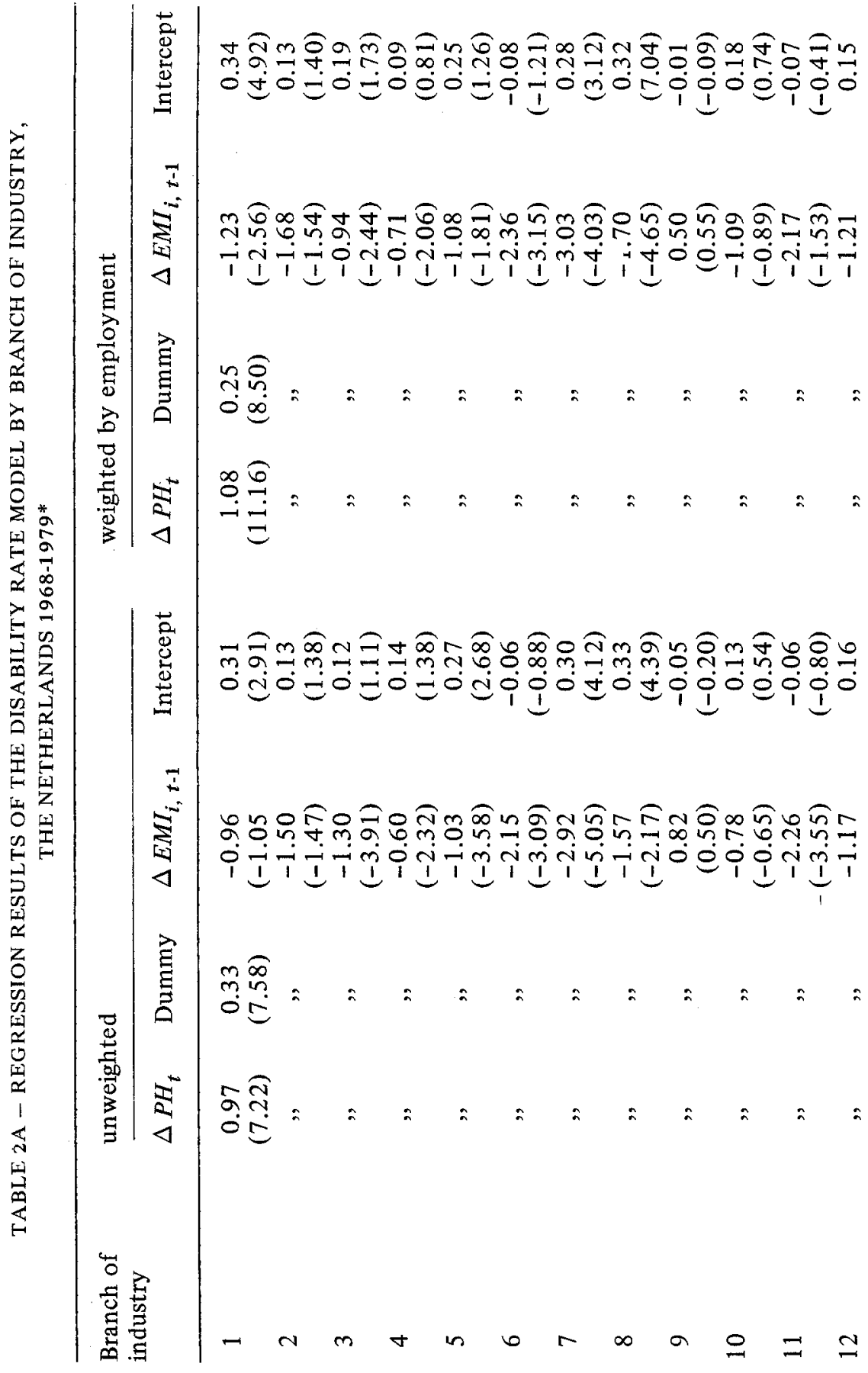




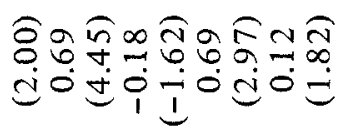

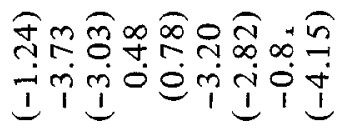

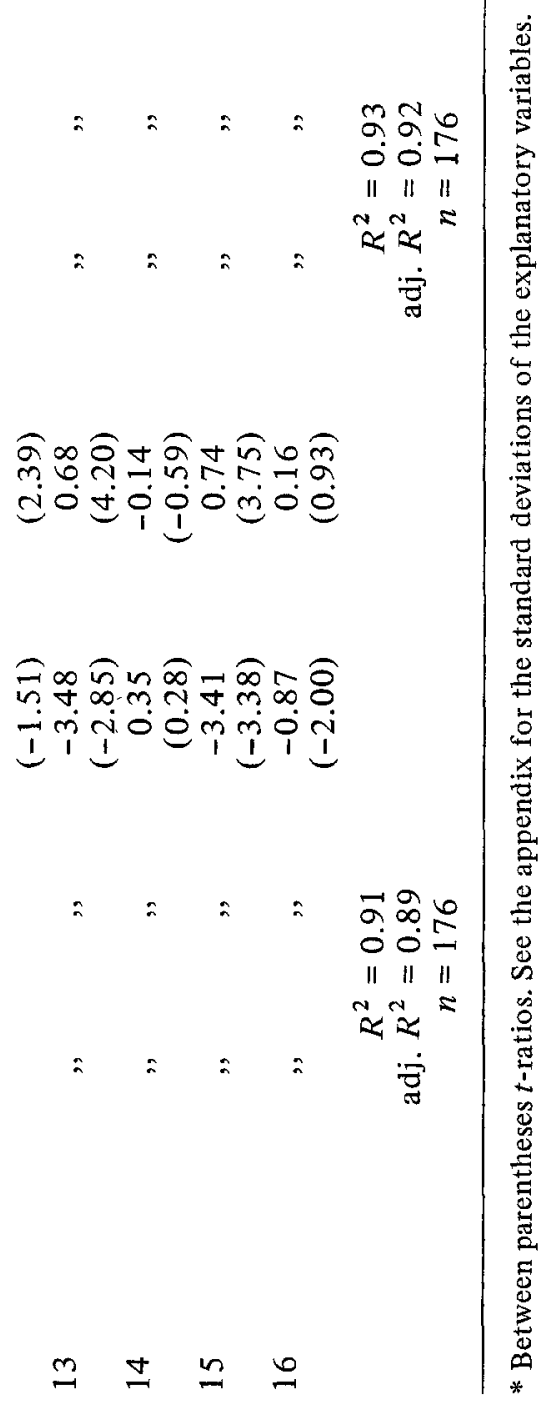




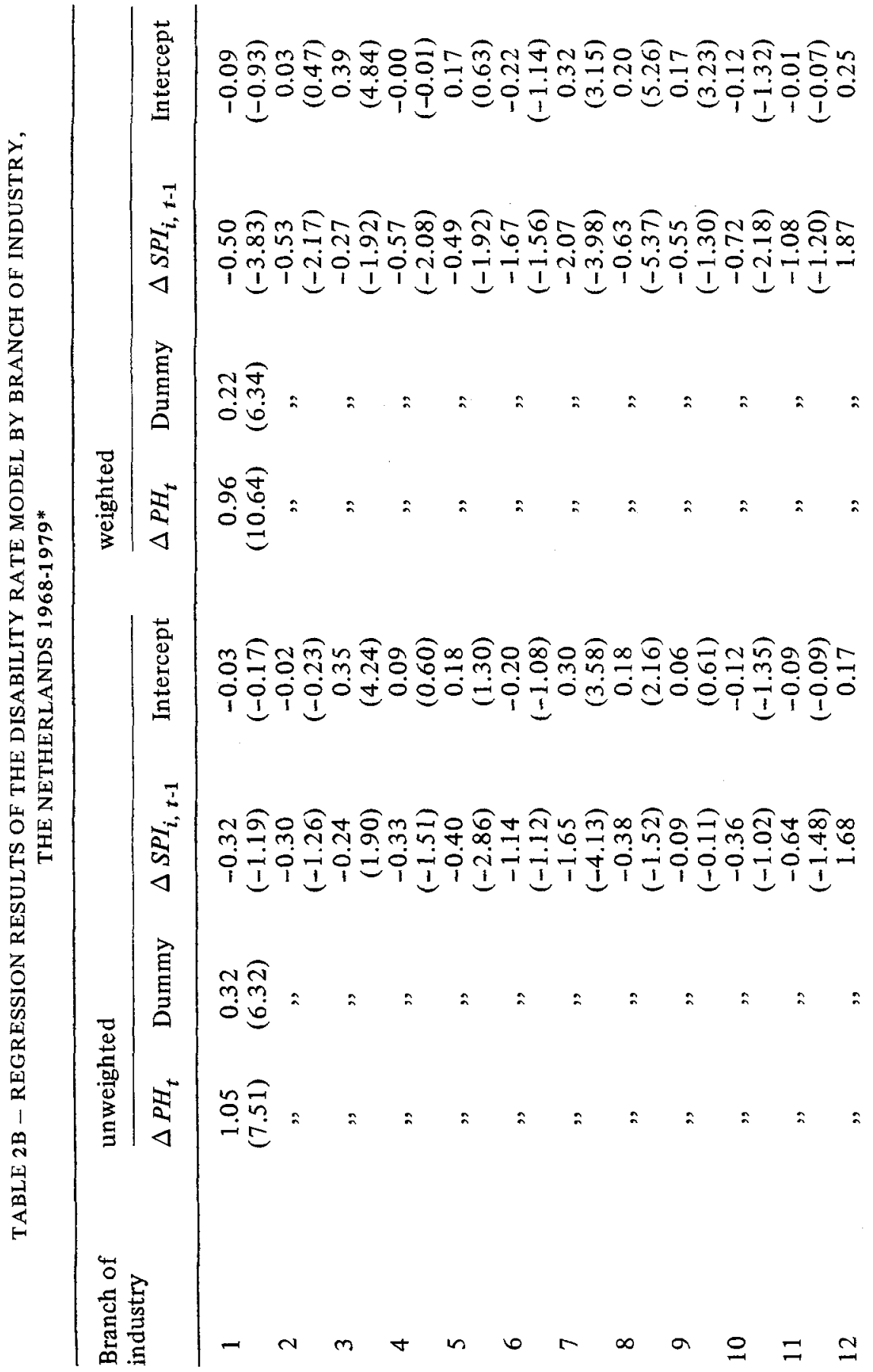




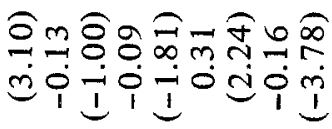

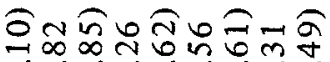

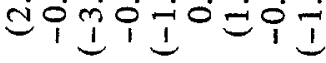

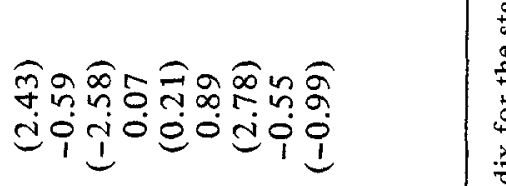

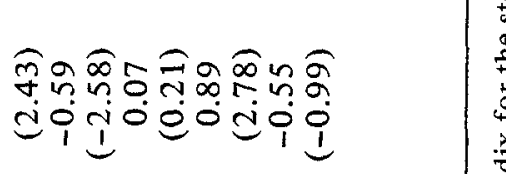

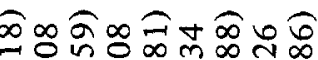

$$
\begin{aligned}
& \text { cióli } \\
& \therefore \quad \therefore \quad \therefore \quad \infty 50
\end{aligned}
$$

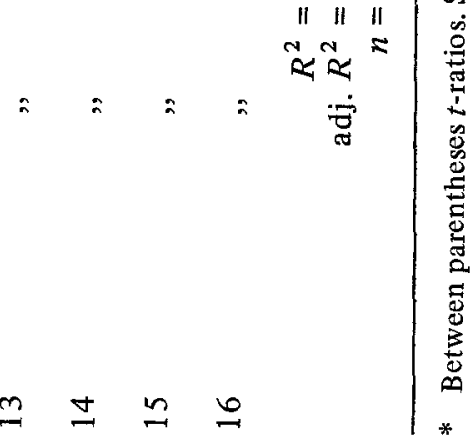


coefficients but two have the expected sign. This means that both a deterioration of the overall perception of health and a worsening of the economic situation will increase the number of disability awards. The only two exceptions with respect to the economic variable are the metal products branch (number 9) and retail trade and crafts (number 14). These branches of industry have a rather low disability incidence rate in the base year 1968 . The trend dummy, which for the period 1968-1974 has the value zero and after that the value 1 , appears to be significant. We would moreover like to draw attention to the fact that the coefficient of the perceived state of health equals approximately one. According to the conceptual framework it follows that a certain change in the disability incidence rate in the public sector, caused by a change in perception of health, will be accompanied by a change of the same magnitude in the disability incidence rate in the private sector.

In general table $2 b$, where the share of profits is used as economic indicator, shows the same results as table $2 \mathrm{a}$. This means among other things that the weighted form again shows a slightly better fit. In this table most coefficients have the expected sign too.

The principal conclusion of the present analysis must be that the results of the regression analysis are in general quite in accordance with our hypothesis, namely that the growth in the disability incidence rate is partly a more or less autonomous process which has taken place in all branches of industry. This results from the evolution of norms and values with respects to the perception of health. On the other hand it appears that the growth of the disability incidence rate is dependent on economic development. Since economic development varies considerably per branch of industry, it follows that the growth of the disability incidence rate will show remarkable differences between the various branches of industry.

\section{CONCLUSION}

The overall conclusion of this paper is that the present analysis per branch of industry confirms the considerable influence of economic factors on the growth of disability transfers. In addition to this a change in a more elusive variable, namely in perception of health, plays a role in the explanation of the growth of the disability transfers, independent of the economic factors. In view of the fact that the economic prospects of most European countries are not very favourable, this means that the costs of social security will not only rise, because of the growing number of unemployed, but also because 
of the growth of the number of disability beneficiaries in the years to come. The opposite side of the coin is that effective employment policies will also result in less disability beneficiaries. In this context it would be interesting to use the present analysis as a starting point for a cross-country study, aimed at explaining the considerable divergence with respect to both disability incidence and disability costs per country. ${ }^{12}$

\section{APPENDIX}

TABLE 1 - STANDARD DEVIATIONS OF THE EXPLANATORY VARIABLES

\begin{tabular}{|c|c|c|c|c|}
\hline $\begin{array}{l}\text { Branch of } \\
\text { industry }\end{array}$ & $\Delta P H_{t}$ & $\Delta S P I_{i, t-1}$ & $\Delta E M I_{i, t-1}$ & Dummy \\
\hline (1) & 0.195 & 0.227 & 0.061 & 0.522 \\
\hline (2) &,$"$ & 0.270 & 0.055 & , \\
\hline (3) & " & 0.507 & 0.171 & , \\
\hline (4) &, & 0.292 & 0.219 & , \\
\hline (5) & ", & 0.449 & 0.198 & , \\
\hline (6) & $"$ & 0.059 & 0.081 & ", \\
\hline (7) & , & 0.158 & 0.100 & , \\
\hline (8) & ", & 0.258 & 0.078 & , \\
\hline (9) & , & 0.075 & 0.032 & ," \\
\hline (10) & ", & 0.180 & 0.044 & , \\
\hline (11) & $"$ & 0.147 & 0.085 & ", \\
\hline (12) & $"$ & 0.086 & 0.072 & , \\
\hline (13) & ", & 0.277 & 0.044 & ", \\
\hline (14) & " & 0.182 & 0.043 & ", \\
\hline (15) & $"$ & 0.200 & 0.055 & , \\
\hline (16) &, & 0.107 & 0.131 & $"$ \\
\hline
\end{tabular}

12 To give an impression of this divergence for five European countries, it appears that the number of disability pensions in force as a percentage of the number of insured, including disability beneficiaries, amounted in Belgium to $4.7 \%$, in Western Germany to $8.8 \%$, Finland $9.9 \%$, France $2.4 \%$ and the Netherlands $10.8 \%$, in 1977 (see Copeland (1981)). 


\section{REFERENCES}

Barro, R.J. and G.M. MacDonald, 'Social Security and Consumer Spending in an International Cross Section,'Journal of Public Economics, XI 1979, pp. 275-289.

Bosch, F.A.J. van den and C. Petersen, Hidden Unemployment and Disability, Discussion Paper Series 7913/G, Institute for Economic Research, Erasmus University Rotterdam, 1979.

Bosch F.A.J. van den and C. Petersen, Arbeidsongeschiktheid en economische ontwikkeling, (with a summary in English), Discussion Paper Series 8102/G, Institute for Economic Research, Erasmus University Rotterdam, 1981a.

Bosch, F.A.J. van den and C. Petersen, Disability as Economic Concept, in: L. Söderström (ed.), 'Arne Ryde Symposium on Social Insurance,' Contributions to Economic Analysis, Amsterdam, 1983 (forthcoming).

Bosch, F.A.J. van den and C. Petersen, 'Een economische analyse van de non-participatiegraad: de invloed van arbeidsongeschiktheid, Maandschrift Economie, XLVI 1982, pp. 307-321.

Bosch, F.A.J. van den, 'Naar een jaargangen benadering van arbeid,' Economisch Statistische Berichten, LXVII 1982, pp. 1300-1305.

Commission of European Communities, Comparative Tables of Social Security Systems, Brussels, 1978.

Copeland, L.S., 'International Trends in Disability Program Growth,' Social Security Bulletin, XIIV (1981), pp. 25-36.

Danziger, S., R. Haveman and R. Plotnick, 'How Income Transfer Programs Affect Work, Savings, and the Income Distribution: A Critical Review,' Journal of Economic Literature, XIX (1981), pp. 975-1028.

Doherty, N.A., 'National Insurance and Absence from Work,' Economic Journal, XIM (1979), pp. 50-65.

Haveman, R. and V. Halberstadt, 'Public Income Support to Disabled Workers: Issues of Program Growth, Costs, and Labor Supply in a Cross-national Context,' in: $\mathbf{M}$. Pfaff (ed.), Effeciency and Effectiveness of Public Transfer Policy, (forthcoming).

Hambor J.C., Unemployment and Disability: an Econometric Analysis with Time Series Data, U.S. Department of Health, Education and Welfare, Social Security Administration, Office of Research and Statistics, Staff Paper, no. 20, Washington, 1975.

Lando, M.E., 'The Effect of Unemployment on Application for Disability Insurance,' Proceedings of the American Statistical Association, Business and Economic Statistics Section, 1974, pp. 438-442.

OECD, 'The Netherlands,' Economic Surveys, Paris, 1981.

Praag, B.M.S. van and V. Halberstadt, 'Towards an Economic Theory of Non-employability: A First Approach,' in: K.W. Roskamp (ed.) Proceedings of the 34th Congress of the International Institute of Public Finance, Hamburg, 1978, Paris, 1980.

Praag, B.M.S. van and H. Emanuel, On the Concept of Non-Employability with Respect to a Non-Homogeneous Labour Force, in: L. Söderström (ed.), 'Arne Ryde Symposium on Social Insurance,' Contributions to Economic Analysis, Amsterdam, 1983 (forthcoming).

Schechter, E.S., 'Commitment to Work and the Self-Perception of Disability,' Social Security Bulletin, XLIV (1981), pp. 22-30. 


\section{Summary}

AN EXPLANATION OF THE GROWTH OF SOCIAL SECURITY DISABILITY TRANSFERS

The purpose of this paper is to provide an explanation for the growth of one of the most important components of social security income transfers: disability benefits to people who withdraw from the labour market as a consequence of becoming disabled. We use a disability model and apply this to branches of industry for the Netherlands (1968-1979). The main conclusion is that the growth of disability incidence rates can to a large degree be explained by worsening of the economic situation. In addition to this a change in another variable, namely perception of health, plays a role in the explanation of the growth fo disability transfers. 